\section{(C) OPEN ACCESS}

\title{
Vertical muscle transposition with silicone band belting in VI nerve palsy
}

\author{
Ricardo Dourado Leite, ${ }^{1}$ Cristina Freitas, ${ }^{1}$ Sandra Guimaraes ${ }^{1,2,3}$
}

\section{${ }^{1}$ Department of Ophthalmology, Hospital de Braga, Braga, Portugal ${ }^{2}$ Life and Health Sciences Research Institute (ICVS), School of Health Sciences, University of Minho, Braga; Portugal \\ ${ }^{3}$ ICVS/3B's - PT Government Associate Laboratory, Braga/Guimarães, Portugal}

\section{Correspondence to} Dr Ricardo Dourado Leite, ricardo.dourado.leite@gmail. com

Accepted 21 November 2016

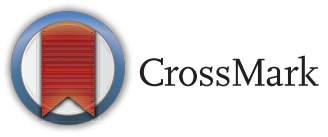

To cite: Dourado Leite $R$, Freitas C, Guimaraes S. BMJ Case Rep Published online: [please include Day Month Year] doi:10.1136/bcr-2016216722

\section{SUMMARY}

A woman aged 60 years developed a Millard-Gubler syndrome after a diagnosis of a cavernous angioma in the median and paramedian areas of the pons. In this context, she presented a right VI nerve palsy, right conjugate gaze palsy, facial palsy and left hemiparesis. To improve the complete VI nerve palsy, we planned a modified transposition approach, in which procedure we made a partial transposition of vertical rectus with a silicone band that was fixated posteriorly. After the procedure, the patient gained the ability to slightly abduct the right eye. We found no compensatory torticollis in the primary position of gaze. There was also an improvement of elevation and depression movements of the right eye. We obtained satisfactory results with a theoretically reversible technique, which is adjustable intraoperatively with no need of muscle detachment, preventing anterior segment ischaemia and allowing simultaneous recession of the medial rectus muscles, if necessary.

\section{BACKGROUND}

In this manuscript, we report a clinical case in which a patient with Millar-Gubler syndrome underwent a surgical procedure to correct her VI nerve palsy. We planned a different technique, a partial transposition of vertical rectus with a silicone band, which represents a natural evolution of the vertical rectus muscles transposition techniques. With this approach, there is no need of tenectomy as well as in Hummelsheim's or Schillinger's approaches (as Jensen also looked for) and there is also no need to split the lateral rectus, a point already achieved with the technique of Inatomi and Nishida (figure 1). With the silicone band transposition, we believe that it also can support the tension of the transposed muscles, in order to ensure the desired surgical results, unlike the muscles sutures onto sclera of the latter authors. As such, this paper should be of interest to a broad readership, including those interested in strabismus surgery.

\section{CASE PRESENTATION}

Six years before the presentation at our department, a woman aged 60 years had a VI left palsy following a diagnosis of a meningioma of the lateral wall of cavernous sinus (figure 2). She had the tumour surgically removed and, 1 year later, she underwent a $3 \mathrm{~mm}$ recession of medial rectus and a $4 \mathrm{~mm}$ resection of lateral rectus of the left eye. After this surgery, her eyes were straight, but afterwards she developed a consecutive exotropia.
Four years later, she was diagnosed a cavernous angioma in the median and paramedian areas of the pons and developed a Millard-Gubler syndrome (figure 3). In this context, she presented at our department with a right VI nerve palsy, right conjugate gaze palsy, right facial palsy, right hipoacusia and left hemiparesis and with symptoms of severe horizontal torticollis (figure 4). The best corrected visual acuity was $3 / 10$ in the right eye and light perception in the left eye, with afferent pupillary defect due to tumour-related optic atrophy. She had torsional nystagmus. Her visual field was compromised by the $>45^{\circ}$ right head turn with total adducing fixing right eye. On the ocular motility examination, we found a complete limitation of abduction and supraduction in the right eye, while adduction could not be correctly evaluated due to fixating in adduction with this only seeing eye; in the left eye, there was a severe limitation in adduction and supraduction, with mild limitation in abduction due to previous medial rectus recession; infraduction was normal in both eyes (figure 5).

\section{TREATMENT}

We planned a surgery in the right eye, with transposition of vertical rectus and a weakening procedure (recession) of the medial rectus. To do both procedures in one-time surgery, the authors planned a modified transposition approach, in which procedure we made a partial transposition of vertical rectus with a silicone band (Labtican Ophtalmics, style\#240 $2.5 \mathrm{~mm}$ circling band) that was fixated posteriorly (figure 6), minimising the risk of anterior ischaemia, and a simultaneous medial rectus recession.

The surgical technique was initiated by a $360^{\circ}$ limbal conjuntival peritomy. The fascia surrounding the inferior, superior and lateral rectus muscles was dissected free. A silicone band was placed belting the lateral halves of the superior (figure $7 \mathrm{~B}$ ) and the inferior (figure $7 \mathrm{~F}$ ) rectus muscles, passing under the lateral rectus muscle (figure 7D). Then, a single-armed 5-0 polyester non-absorbable braided fixation suture was used to fixate the lateral halves of the vertical rectus muscles to the band and then the band to the sclera $16 \mathrm{~mm}$ posterior to the limbus in each temporal quadrant (figure 7G-I). The sleeve (Labtican Ophtalmics, style\#270 silicone sleeve 5/Box) was placed in the superior temporal quadrant (figure $7 \mathrm{I}$ ), where the silicone band was pulled tight and tied in position to shorten the distance between the vertical rectus muscles and the lateral rectus, to change the force vectors of the 

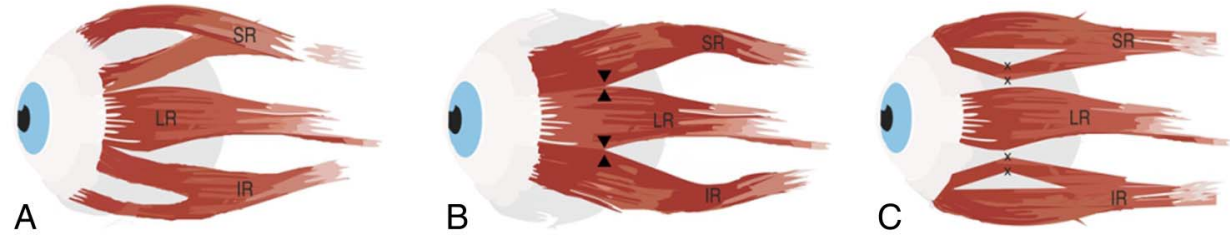

Figure 1 Schematic representations of vertical rectus transpositions in sixth nerve palsies. The operative eye in the figure is a left eye. (A) Hummelsheim; (B) Foster-augmented transposition; (C) Inatomi and Nishida. LR, lateral rectus, SR, superior rectus, IR, inferior rectus.
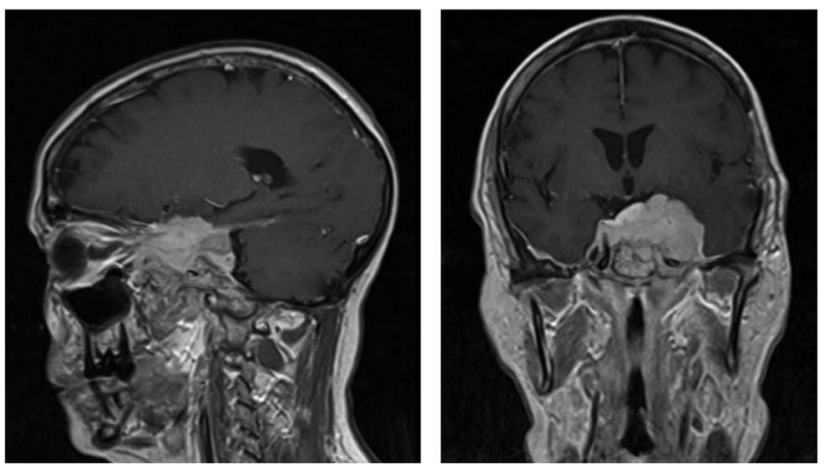

Figure 2 Sagital and coronal contrast MRI T1-weighting showing the meningioma of the lateral wall of cavernous sinus.
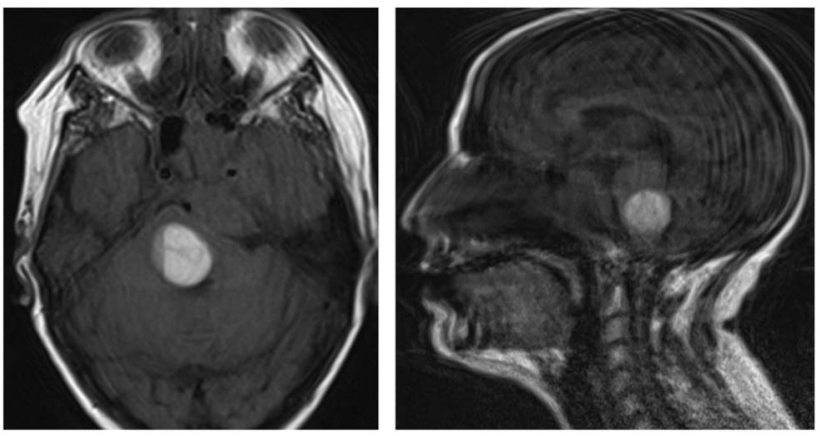

Figure $3 \mathrm{MRI}$ images demonstrating the cavernous angioma of the pons (artefacts due to poor collaboration of the patient).

muscles, increasing their passive elastic forces and creating a tone through the transposed muscles in the primary position. Finally, an $11 \mathrm{~mm}$ recession of the medial rectus muscle was then performed (figure $7 \mathrm{~J}$ ). The conjunctiva was closed with 8-0 polyglactin suture.

\section{OUTCOME AND FOLLOW-UP}

After the procedure, the patient gained the ability to slightly abduct the right eye. We found no compensatory torticollis in the primary position of gaze. There was also an improvement of elevation and depression movements of the right eye (figure 8).

\section{DISCUSSION}

Hummelsheim was the first to describe the use of vertical rectus muscles in cases of complete sixth nerve palsy: the lateral halves of the superior and inferior rectus muscles were transposed to the lateral rectus insertion as a method to improve abduction. ${ }^{1}$ Since then, a variety of transposition procedures have been proposed. ${ }^{2}$ In 1959 , Schillinger ${ }^{3}$ reported a full tendon transposition that changes the force vectors of the transposed vertical muscles. In 1997, Foster ${ }^{4}$ described a modification of this technique, with

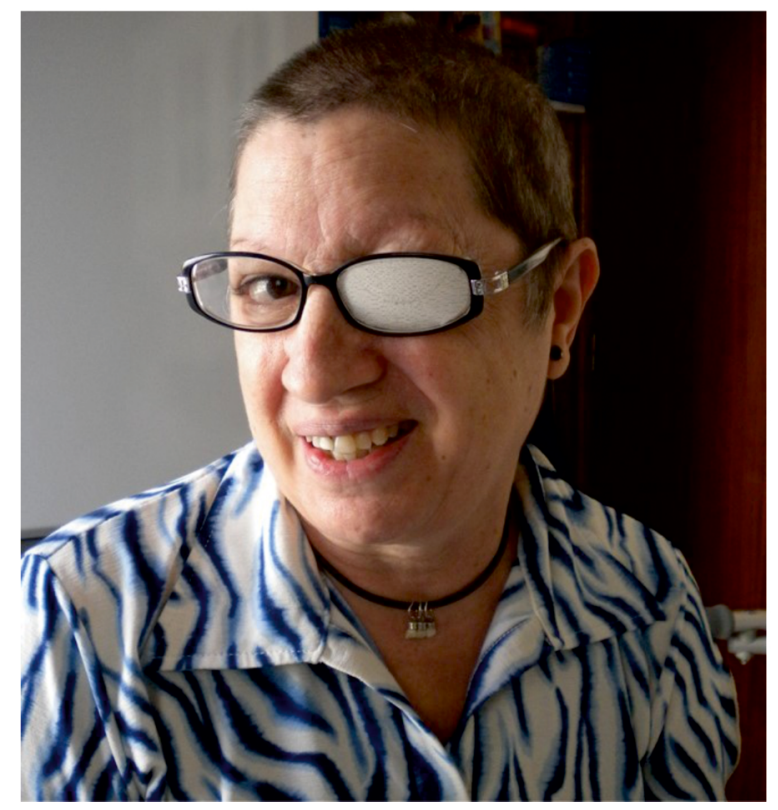

Figure 4 Horizontal torticollis.

vertical rectus full tendon transposition augmentation using nonabsorbable sutures to enhance lateralisation of each transposed rectus muscle, reducing the space between the muscles and increasing the effect of the procedure. In 2003, Inatomi and Nishida introduced another technique where the lateral halves of the vertical muscles were sutured onto the sclera, sparing lateral muscle splitting or transposition. ${ }^{5}$

Silicone bands have already been used in strabismus surgery for several years. Its application include surgeries for myopic esotropia and strabismus fixus, ${ }^{6} 7$ manifest exotropia, ${ }^{7}$ superior oblique muscle approaches ${ }^{8} 9$ and may be also used as an alternative to the retroequatorial myopexy. ${ }^{10}$

Achieving acceptable postoperative alignment is difficult in patients with complete abducens palsy. The main goal is orthotropia in the primary position of gaze. The method of surgical treatment of VI nerve palsy depends on the degree of paresis/ palsy of the affected lateral rectus. In incomplete paresis, horizontal rectus muscle surgery is the procedure of choice, whereas cases of complete paresis are best managed with a muscle transposition; a medial rectus recession is usually necessary.

We want to show that a transposition procedure can be performed simultaneously with medial rectus surgery. If we use a silicone band, there is no need of tenectomy or muscle detachment and some of the anterior circulation is left intact, minimising anterior segment ischaemia. Moreover, there is no need to split the lateral rectus, avoiding its displacement or surgical trauma. On the other hand, we believe that it also can support the tension of the transposed muscles, in order to ensure the 
Figure 5 Preoperative photographs in different positions of gaze.
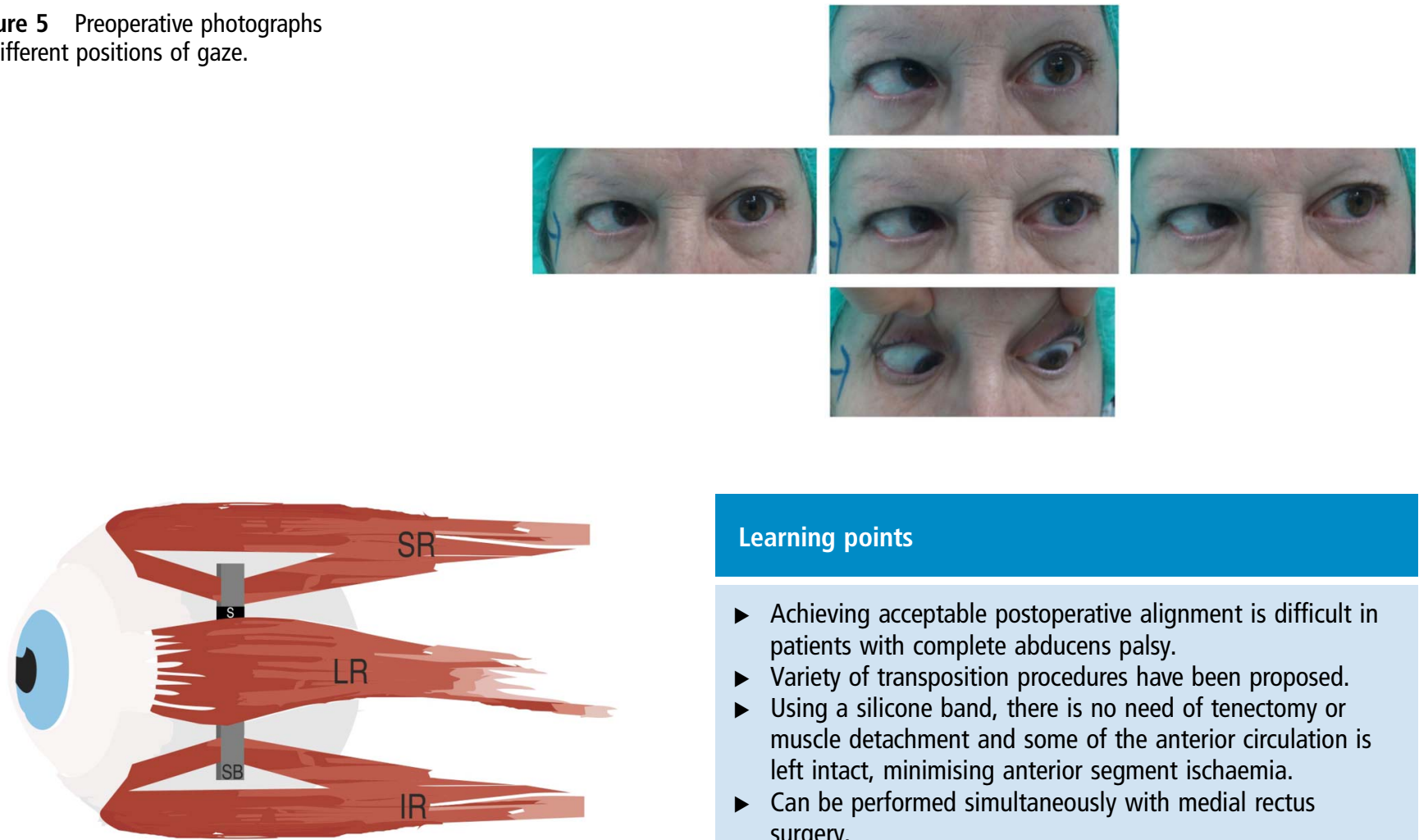

Learning points

- Achieving acceptable postoperative alignment is difficult in patients with complete abducens palsy.

- Variety of transposition procedures have been proposed.

- Using a silicone band, there is no need of tenectomy or muscle detachment and some of the anterior circulation is left intact, minimising anterior segment ischaemia.

- Can be performed simultaneously with medial rectus surgery.

Figure 6 Vertical muscle transposition with silicone band belting. $L R$, lateral rectus, SR, superior rectus, IR, inferior rectus, SB, silicone band, $S$, sleeve.
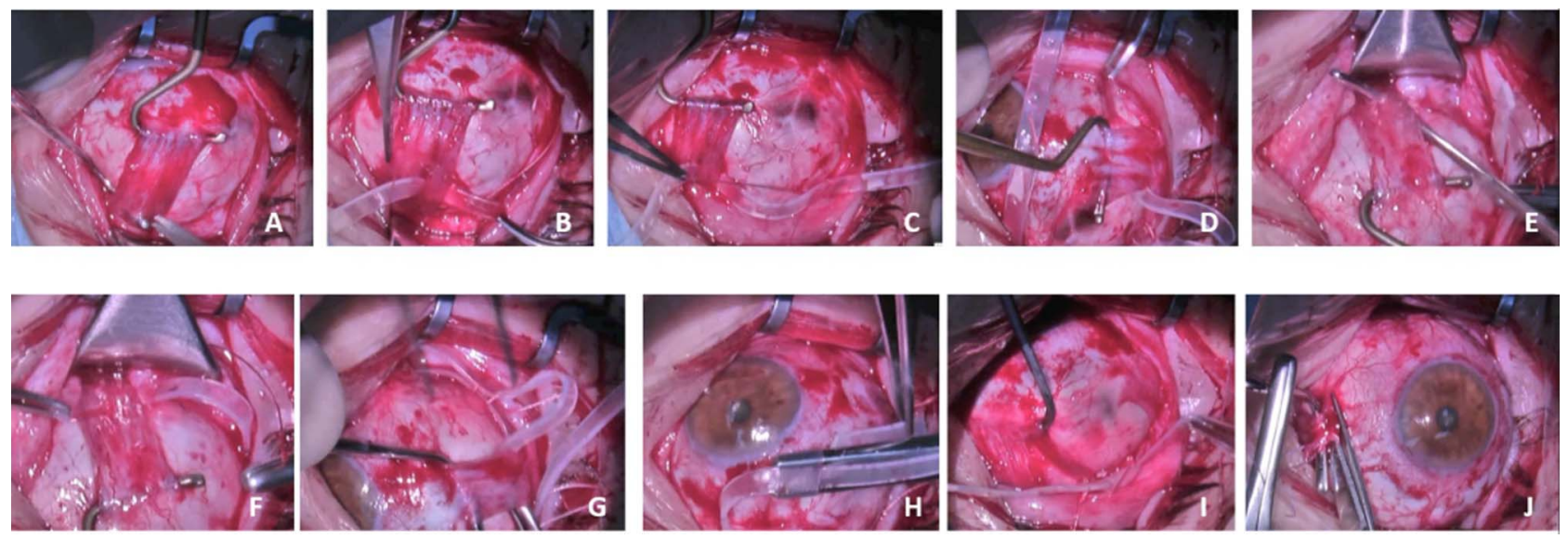

Figure 7 Intraoperative pictures illustrating the steps of the surgical technique.

Figure 8 Postoperative pictures showing the improvement of torticollis and ocular motility in the different positions of gaze.
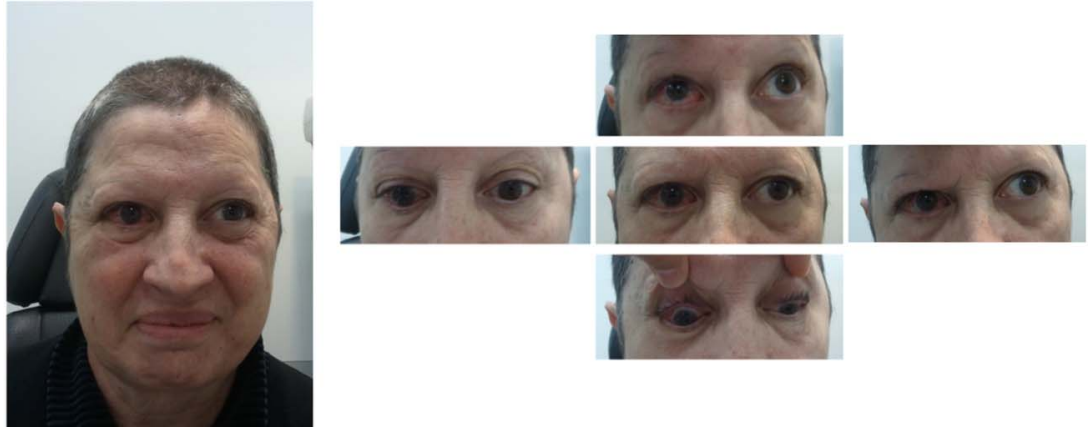


\section{Novel treatment (new drug/intervention; established drug/procedure in new situation)}

desired surgical results, unlike the muscles sutures onto sclera. As such, it is a theoretically reversible approach that is adjustable intraoperatively as the silicone band can be tightened as needed and also retains all the advantages of the vertical muscles transpositions and the posterior fixation technique.

Contributors The idea of creating this modification of vertical muscle transposition with Silicone Band Belting in VI nerve palsy came from SG. SG, CF and RDL performed the surgical technique. RDL was in charge of drafting the publication, always with the collaboration of both colleagues. The three coauthors have participated in the preparation of this publication accordingly.

Competing interests None declared.

Patient consent Obtained.

Provenance and peer review Not commissioned; externally peer reviewed.

Open Access This is an Open Access article distributed in accordance with the Creative Commons Attribution Non Commercial (CC BY-NC 4.0) license, which permits others to distribute, remix, adapt, build upon this work non-commercially, and license their derivative works on different terms, provided the original work is properly cited and the use is non-commercial. See: http://creativecommons.org/ licenses/by-nc/4.0/

\section{REFERENCES}

1 Hummelshein E. Uber Schnentransplantation am Ague. Ophthal Gesselschft 1907:34:248.

2 Gunton KB. Vertical rectus transpositions in sixth nerve palsies. Curr Opin Ophthalmol 2015;26:366-70.

3 Schillinger RJ. A new type of tendon transplant operation for abducens paralysis. J Int Coll Surg 1959;31:593.

4 Foster RS. Vertical muscle transposition augmented with lateral fixation. J Am Assoc Pediatr Ophthalmol Strabismus 1997;1:20.

5 Sabetti L, Berarducci A, Lodovico DD. Silicone band loop myopexy in treatment of myopic strabismus fixus: surgical outcome of a novel modification. Open J Ophthalmol 2013;3:1-3.

6 Wong I, Leo SW, Khoo BK, et al. Loop myopexy for treatment of myopic strabismus fixus. J AAPOS 2005;9:589-91.

7 Sabetti L, Berarducci A, Lodovico DD. Silicone band in the surgical treatment of manifest exotropia. Open J Ophthalmol 2013;3:1-3.

8 Awadein A, Gawdat G. Comparison of superior oblique suture spacers and superior oblique silicone band expanders. J AAPOS 2012;16:131-5.

9 Greenberg MF, Pollard ZF. Treatment of inferior oblique paresis with superior oblique silicone tendon expander. J AAPOS 2005;9:341-5.

10 Kutschan A, Schroeder B, Schroeder W. Is bimedial muscle belting an alternative procedure to retroequatorial myopexy in convergence excess esotropia? Ophthalmologe 2007;104:582-7.

Copyright 2016 BMJ Publishing Group. All rights reserved. For permission to reuse any of this content visit http://group.bmj.com/group/rights-licensing/permissions.

BMJ Case Report Fellows may re-use this article for personal use and teaching without any further permission.

Become a Fellow of BMJ Case Reports today and you can:

- Submit as many cases as you like

- Enjoy fast sympathetic peer review and rapid publication of accepted articles

- Access all the published articles

Re-use any of the published material for personal use and teaching without further permission

For information on Institutional Fellowships contact consortiasales@bmjgroup.com

Visit casereports.bmj.com for more articles like this and to become a Fellow 